\title{
The effect of an online exercise programme on bone health in paediatric cancer survivors (iBoneFIT): study protocol of a multi-centre randomized controlled trial
}

Jose J. Gil-Cosano ${ }^{1 \dagger}$, Esther Ubago-Guisado ${ }^{1 \dagger}$, Maria J. Sánchez ${ }^{2,3,4,5}$, Maria J. Ortega-Acosta ${ }^{6}$, Maria E. Mateos ${ }^{7,8}$, Ana I. Benito-Bernal ${ }^{9}$, Francisco J. Llorente-Cantarero ${ }^{8,10,11}$, Francisco B. Ortega' ${ }^{1}$, Jonatan R. Ruiz ${ }^{1}$, Idoia Labayen ${ }^{12}$, Vicente Martinez-Vizcaino ${ }^{13,14}$, Dimitris Vlachopoulos ${ }^{15}$, Manuel Arroyo-Morales ${ }^{16,17,18}$, Manuel Muñoz-Torres ${ }^{19,20,21}$, Juan F. Pascual-Gázquez ${ }^{6}$, Maria C. Vicho-González ${ }^{7}$ and Luis Gracia-Marco ${ }^{1 *}$ (i)

\begin{abstract}
Background: New approaches on paediatric cancer treatment aim to maintain long-term health. As a result of radiotherapy, chemotherapy or surgery, paediatric cancer survivors tend to suffer from any chronic health condition. Endocrine dysfunction represents one of the most common issues and affects bone health. Exercise is key for bone mass accrual during growth, specifically plyometric jump training. The iBoneFIT study will investigate the effect of a 9-month online exercise programme on bone health in paediatric cancer survivors. This study will also examine the effect of the intervention on body composition, physical fitness, physical activity, calcium intake, vitamin D, blood samples quality of life and mental health.

Methods: A minimum of 116 participants aged 6 to 18 years will be randomized into an intervention $(n=58)$ or control group $(n=58)$. The intervention group will receive an online exercise programme and diet counselling on calcium and vitamin D. In addition, five behaviour change techniques and a gamification design will be implemented in order to increase the interest of this non-game programme. The control group will only receive diet counselling. Participants will be assessed on 3 occasions: 1) at baseline; 2) after the 9 months of the intervention; 3) 4 months following the intervention. The primary outcome will be determined by dual energy X-ray absorptiometry (DXA) and the hip structural analysis, trabecular bone score and 3D-DXA softwares. Secondary outcomes will include anthropometry, body composition, physical fitness, physical activity, calcium and vitamin D intake, blood samples, quality of life and mental health.

(Continued on next page)
\end{abstract}

\footnotetext{
* Correspondence: Igracia@ugr.es

† Jose J. Gil-Cosano and Esther Ubago-Guisado contributed equally to this

work.

"PROFITH "PROmoting FITness and Health through Physical Activity"

Research Group, Sport and Health University Research Institute (iMUDS),

Department of Physical Education and Sports, Faculty of Sport Sciences,

University of Granada, 18071 Granada, Spain

Full list of author information is available at the end of the article
}

\section{$\triangle B M C$}

(c) The Author(s). 2020 Open Access This article is licensed under a Creative Commons Attribution 4.0 International License, which permits use, sharing, adaptation, distribution and reproduction in any medium or format, as long as you give appropriate credit to the original author(s) and the source, provide a link to the Creative Commons licence, and indicate if changes were made. The images or other third party material in this article are included in the article's Creative Commons licence, unless indicated otherwise in a credit line to the material. If material is not included in the article's Creative Commons licence and your intended use is not permitted by statutory regulation or exceeds the permitted use, you will need to obtain permission directly from the copyright holder. To view a copy of this licence, visit http://creativecommons.org/licenses/by/4.0/ The Creative Commons Public Domain Dedication waiver (http://creativecommons.org/publicdomain/zero/1.0/) applies to the data made available in this article, unless otherwise stated in a credit line to the data. 
(Continued from previous page)

Discussion: Whether a simple, feasible and short in duration exercise programme can improve bone health has not been examined in paediatric cancer survivors. This article describes the design, rationale and methods of a study intended to test the effect of a rigorous online exercise programme on bone health in paediatric cancer survivors. If successful, the iBoneFIT study will contribute to decrease chronic health conditions in this population and will have a positive impact in the society.

Trial registration: Prospectively registered in isrctn.com: isrctn61195625. Registered 2 April 2020.

Keywords: Telemedicine, Cancer, Survivor, Bone, Plyometric exercise, Paediatrics, Quality of life

\section{Background}

Owing to major advances in cancer screening and treatment over the last 30 years, cancer survival has improved dramatically. In Europe, the paediatric cancer incidence increases annually by $0.54 \%$ in children ( $0-14$ years) and by $0.96 \%$ in adolescents (15-19 years), although it seems that the incidence in adolescents is decelerating [1]. Nevertheless, the 5-year survival rate is now at $77.9 \%$ for children and $79 \%$ for adolescents and young adults (2039 years) [2, 3]. Unfortunately, the treatment of paediatric cancer by means of radiation, chemotherapy and/or surgery is associated with various late effects (e.g. impaired growth, musculoskeletal sequelae, cardiopulmonary compromise and secondary malignancy) [4-6], predisposing paediatric cancer survivors to disabling conditions [4]. Furthermore, paediatric cancer treatment has been documented to have an effect on emotional well-being and quality of life, with survivors reporting anxiety, depression and post-traumatic stress $[7,8]$.

Paediatric cancer is a life-threatening condition that also occurs during the period of bone development and strengthening. Gonadal failure following to pelvic radiation or gonadotoxic chemotherapy and hypothalamic pituitary dysfunction by means of cranial radiation can adversely affect areal bone mineral density (aBMD), increasing osteoporosis risk later in life $[9,10]$. In addition, direct radiation to bone not only causes hypovascularity but has a direct cytotoxic effect on the epiphyseal chondrocytes [11]. Observational studies have found low aBMD during and after cancer treatment to be associated with increased fracture risk (80\% increase for every 1 SD reduction in lumbar spine aBMD Z-score) [12-15], which can lead to a higher risk of osteopenia and osteoporosis in adulthood and finally, disability [16, 17]. Moreover, data from a review showed that up to $68 \%$ of paediatric cancer survivors presented moderate-tosevere aBMD deficits (Z-score $<-1$ ), while up to $46 \%$ had severe aBMD deficits (Z-score $<-2$ ) [18].

The attainment of peak bone mass during childhood and adolescence determines the aBMD later in life and therefore the onset of osteoporosis [19, 20]. This process has a strong genetic component, although lifestyle factors (i.e. physical activity and dietary habits) contribute up to $20 \%$ of the variation in peak bone mass [21]. Highintensity, weight bearing physical activity that elicit a variety of strains and include multiple rest periods is known to improve bone mass [22-25], accrual [26] and maintenance [27] as the skeleton adapts to the loads under which it is placed. Likewise, an adequate calcium and vitamin $\mathrm{D}$ intake in combination with physical activity is necessary to obtain beneficial gains in bone health in children and adolescents [28, 29]. In this sense, calcium and vitamin D supplementation did not add benefit to nutritional counselling for improving bone outcomes among adolescents and young adults survivors of acute lymphoblastic leukaemia [30].

\section{Exercise and bone health}

Exercise contributes to the development of bone mass in youths due to its association with increases in lean mass $[31,32]$. Larger muscles exert greater forces on the bones, which will adapt and therefore improve their strength [33]. Furthermore, plyometric jump training is one of the best methods to improve bone health since the impacts produced against the ground will cause higher forces on the bones [34]. A recent systematic review has shown that plyometric jump training causes improvements in bone mineral content (BMC), aBMD and structural properties in children and adolescents [35]. More specifically, an 8-month jumping intervention ( $\sim 3 \mathrm{~min} /$ day) improved bone mass in the proximal femur in pubertal children [36]. Mackelvie et al. [37] showed that a 7 -month jumping intervention $(10 \mathrm{~min}, 3$ times/week) enhanced bone mass in the femoral neck and lumbar spine in pubertal girls. Additionally, Vlachopoulos et al. [38, 39] found that a 9-month jumping intervention ( $10 \mathrm{~min}, 3$ to 4 times/week) improved bone outcomes in adolescent males participating in nonosteogenic sports and with poorer bone health.

A similar effect might be seen in survivors of paediatric cancer. A randomized controlled trial (RCT) in children with acute lymphoblastic leukaemia showed that resistance exercise was unsuccessful in preventing the reduction in aBMD [40]. However, the intervention (duration, load) was not properly described. A RCT focusing on low-magnitude, high frequency mechanical 
stimulation seemed to improve total body aBMD in paediatric cancer survivors, while a reduction was observed in the placebo group [41]. In a recent study in children with cancer, the exercise programme was not successful in improving aBMD nor other factors such as physical function or health-related quality of life [42]. This was because exercise requires of certain intensity to modify these factors and this could not be achieved during treatment due to the child's responses to the treatment and disease. Considering the gap in the literature, and taking into account the Exercise Guidelines for Cancer Survivors [43, 44], it is crucial to develop and implement feasible exercise programmes focused on improving bone health into survivorship.

The aim of this study is to investigate the effect of a 9month online exercise programme on bone health in paediatric cancer survivors aged 6-18 years and to follow up these outcomes 4 months after the intervention to determine the extent of residual effect. We hypothesize that the intervention stimulus will be enough to improve bone health in this population. We will also examine the effect of the intervention on body composition, physical fitness, physical activity, calcium intake, vitamin D, blood samples quality of life and mental health.

\section{Methods/ design}

\section{Study design}

This protocol is reported based on Standard Protocol Items: Recommendations for Interventional Trials (SPIR IT) guidelines [45]. The iBoneFIT study is a multicentre, parallel groups RCT (1:1) designed under the equivalence basis and registered in isrctn.com (Reference: isrctn61195625, 2 April 2020). Eligible participants from two paediatric oncology units of Southern Spain will be contacted, informed, and if consenting, enrolled into the study after a meeting $\left(\mathrm{T}_{-1}\right)$ (see recruitment section). Then, randomization will be performed by an external partner who is independent of the participant recruitment and enrolment process (see randomization section). Assessments will be conducted at baseline $\left(\mathrm{T}_{0}\right)$ and after nine $\left(T_{1}\right)$ and thirteen $\left(T_{2}\right)$ months in the Sport and Health University Research Institute (iMUDS, University of Granada). After finishing the study, participants in the control group will be offered the same online exercise programme. A graphical description of the study design is shown in Fig. 1.

\section{Ethical approval}

The study will be performed following the ethical guidelines of the Declaration of Helsinki, last modified in 2013. This study has been checked and approved by the Ethics Committee on Human Research of Regional Government of Andalusia (Reference: 4500, December 2019).

\section{Inclusion and exclusion criteria}

The iBoneFIT study will include paediatric cancer survivors: 1) aged 6 to 18 years; 2) diagnosed at least 1 year earlier; 3) to have been exposed to radiotherapy and/or chemotherapy; and 4) not currently receiving treatment for cancer.

Exclusion criteria are defined as follows: 1) simultaneous participation in another study that place participants at any additional risk, discomfort or affect the results of both studies; 2) previous diagnosed anorexia nervosa/bulimia, known pregnancy and/or known alcohol and drug abuse; 3) children requiring chronic oral glucocorticoid therapy; 4) having an injury that may affect daily life activities and can be aggravated by exercise; and 5) to have a lower limb prosthesis that prevent bone assessment.

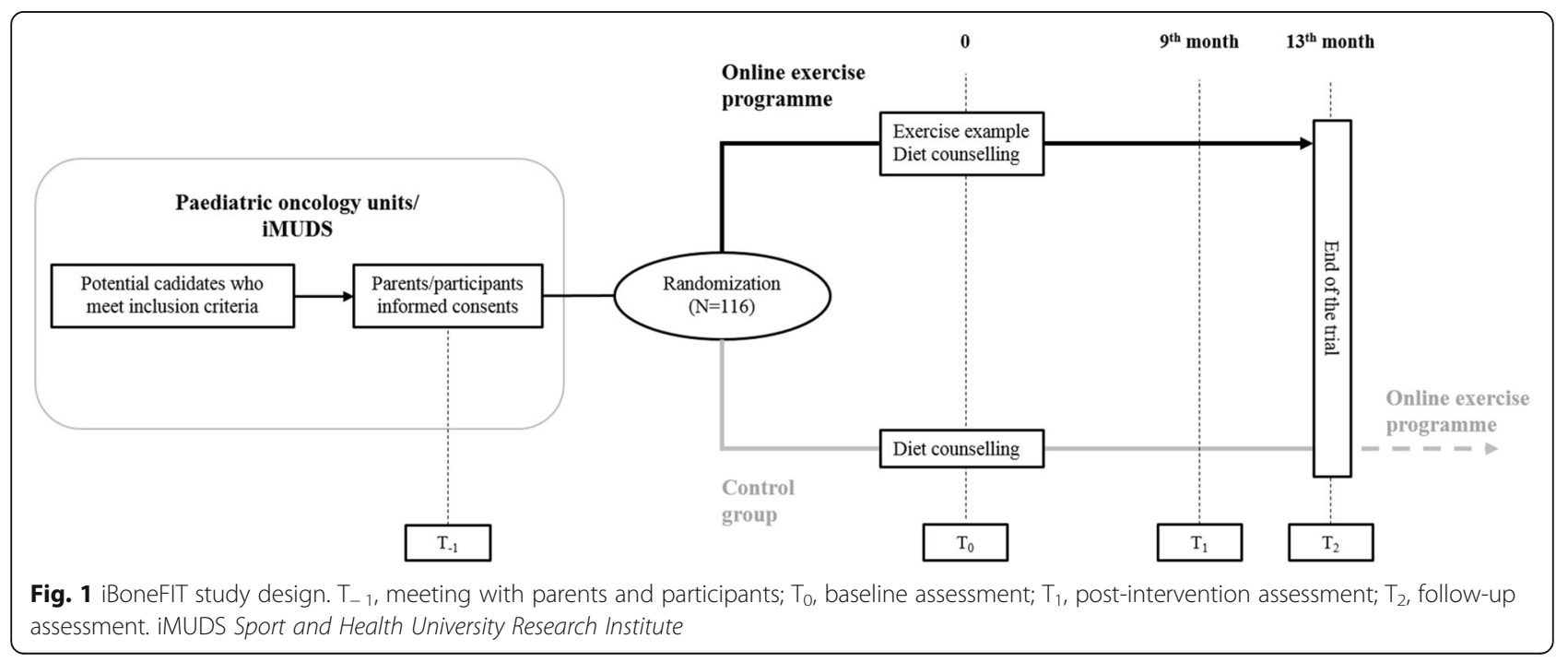




\section{Recruitment}

Eligible participants will be contacted via telephone calls or information letters from the Units of Paediatric Oncology of the 'Virgen de las Nieves' (Granada) and 'Reina Sofía' (Córdoba) University Hospitals in Southern Spain. A short study information brochure will be used in routine check-ups. A meeting will be held with potential participants and parents/tutors to carefully inform about the benefits and risks of the study, and researchers will answer any question that they may have. Then, informed consents will be given, and participants will have 15 days to send it to the researchers. A hotline will be available to clarify remaining questions about the study. Those who do not react to the study invitation will be followed up via phone call at the end of these 15 days in order to check if they wish to participate. All participants will sign the informed consent before their visit to the iMUDS.

\section{Randomization and blinding}

Randomization to an intervention group (online exercise programme, IG) or control group (no treatment, CG) will be performed by an external partner (V.M-V) who is independent of the participant recruitment and enrolment process, stratified by age and sex. Each participant will be provided a uniform $(0,1)$ random number using SAS software, version 9.1 (SAS Institute Inc), within their respective age and sex group. Assignments will be blinded to the assessors until all tests are completed. For feasibility reasons, the study will probably be conducted in two waves of 58 children at most.

\section{Sample size}

We have used femoral neck aBMD as the outcome to calculate the sample size, since it is a key variable in the diagnosis of osteoporosis. Since the study will include children and adolescents (6-18 years), the sample size has been calculated taking into account that sub-group analysis by age groups (6 to 11 years and 12 to 18 years) may be required. Based on an expected effect size of 0.25 for the change in femoral neck aBMD, an $\alpha$ level of 0.05 and a power of $80 \%$, a minimum of 116 participants will be required $(\mathrm{IG}=58$ and $\mathrm{CG}=58)$. This includes a $20 \%$ extra for occasional losses and refusals and $10 \%$ for multivariable analyses. Calculations have been obtained using G*Power (v.3.1.9.2) with analysis of variance: repeated measures (within-between interactions) for 2 groups (between factors) and 2 time points (pre, post, within factors). A correlation between measures of 0.7 has been assumed, which is achievable when measuring bone outcomes [16].

\section{Statistical analysis}

All variables will be checked for normality using both statistical and graphical methods. Results will be presented as frequencies and proportions with $95 \%$ confidence intervals for categorical variables and mean (standard deviation) or median (range) for continuous variables. A descriptive analysis of the participants characteristics will be performed as soon as the baseline assessments are completed. This cross-sectional analysis will show the comparability of IG and CG and the need for adjustment when between group comparisons are done.

General Lineal Models will be used to examine the training effects [time (pre-post 9-month intervention) $\mathrm{x}$ group interaction] on the primary and secondary outcomes. Change in bone outcomes will be used as age and sex-adjusted z-scores. The baseline level of each outcome variable will be entered as covariate. Effect sizes will be reported. Multiple imputation methods and sensitivity analysis (i.e. propensity score) will be performed to handle missing data and appreciate the potential influence of missing responses. Finally, in the event of possible dropouts, a statistical analysis will be carried out by protocol and intention to treat.

\section{Participant adherence and compliance}

Participants will be allowed to withdraw at any time; nevertheless, several strategies will be used for adherence and compliance with the intervention. The minimum compliance allowed at each phase of the intervention will be $50 \%$ but the overall compliance after 9 months will have to reach $70 \%$. A lack of compliance $(<50 \%)$ without justified reasons in the first phase of the intervention will result in the participant being invited to drop out from the study. This $70 \%$ adherence rate means completing 95 sessions of 136 . If a participant has not completed $70 \%$ of the intervention by the end of the 9 months but can reach $70 \%$ within two additional weeks, the exercise programme will be extended for them. Compliance with the intervention will be monitored using a diary and it will be sent to the research staff on a monthly basis (Item 5). Parental involvement will be requested for this matter.

Participants and their parents are verbally motivated to participate in the intervention and to attend to all the assessments. Children who complete successfully the intervention will get a certificate of achievement. Children are the key part of this study and they deserve acknowledgements for their positive attitude and willingness (and their family) to participate in this study.

\section{Intervention}

\section{Exercise programme rationale}

The rationale of the iBoneFIT exercise programme will be described following the Consensus on Exercise Reporting Template (CERT) criteria recommendations [46]. The items detailing the recommendations are shown in Table 1. 
Table 1 CERT checklist from iBoneFIT study exercise programme

\begin{tabular}{lll}
\hline Item & Checklist item & Identification (section) \\
\hline 1 & Detailed description of exercise equipment & Exercise programme characteristics \\
3 & Detailed description of the qualifications, expertise and/or training & Exercise programme characteristics \\
4 & Describe whether exercises are performed individually or in a group & Exercise programme characteristics \\
5 & Describe whether exercises are supervised or unsupervised; how they are delivered & Exercise programme characteristics \\
6 & Detailed description of how adherence to exercise is measured and reported & Participant adherence and compliance \\
$7 \mathrm{a}$ & Detailed description of motivation strategies & Exercise programme characteristics \\
$7 \mathrm{~b}$ & Detailed description of the description rule(s) determining exercise progression & Exercise programme rationale \\
8 & Detailed description of how the exercise programme was progressed & Periodisation \\
9 & Detailed description of each exercise to enable replication & Session structure \\
10 & Detailed description of any home programme component & Exercise programme rationale \\
11 & Describe whether there are any non-exercise components & Control group \\
12 & Describe the type and number of adverse events that occur during exercise & Exercise programme characteristics \\
13 & Describe the setting in which the exercises are performed & Exercise programme characteristics \\
$14 \mathrm{a}$ & Detailed description of the exercise intervention & Intervention \\
$14 \mathrm{~b}$ & Describe whether the exercises are generic (one size fits all) or tailored & Exercise programme characteristics \\
15 & Detailed description of how exercises are tailored to the individual & Exercise programme characteristics \\
$16 \mathrm{a}$ & Describe the decision rule for determining the starting level & Describe how adherence or fidelity is assessed/measured \\
$16 \mathrm{~b}$ & Describe the extent to which intervention was delivered as planned & Exercise programme rationale \\
\hline
\end{tabular}

Since plyometric jump training has been shown to be effective in improving bone health and to maintain the benefits after the intervention in children and adolescents [35], jumping exercise will be the basis for the specific exercise type in iBoneFIT. Notwithstanding, the Exercise Guidelines for Cancer Survivors recommend an extended phase of resistance training before progressing to impact loading [44]. In this sense, a recent systematic review highlighted that resistance training should be incorporated at an early age and prior to plyometric training in order to establish an adequate foundation of strength for power training activities [47]. Therefore, all participants will start with a familiarisation phase aimed to improve muscular fitness before implementing mechanical loading through jumps (Item 7a and 15).

Although the duration of the jumping interventions to be effective on bone outcomes in children and adolescents is unclear, the length of the exercise programme will be 9 months based on results from previous studies [38, 48]. In addition, we have considered the fact that bone remodelling process requires approximately 5 months [49]. Dietary counselling on calcium and vitamin $\mathrm{D}$ will be provided to the participants in both control and intervention groups due to having an adequate calcium and vitamin D levels is important as both interact with physical activity to enhance bone mass (Item 9) [28, 50].

\section{Exercise programme characteristics}

This home-based intervention will be delivered online by making use of social media (Item 4 and 12). Using popular existing social network sites may address issues of reach, engagement, and retention [51, 52]. WhatsApp (WhatsApp Inc., Mountain View, CA, USA) is a highly used app in Spain for social networking and that allows us to send text messages and other types of media (e.g. photos and videos) to the parents of participants. Although WhatsApp has been revealed as a feasible method to deliver exercise interventions, Muntaner-Mas et al. [53] have suggested that the implementation of behaviour change techniques could increment the effectiveness on the outcomes assessed. Thus, five behaviour change techniques (i.e. action planning and goal setting, providing instructions and demonstrations of how to perform the behaviour, self-monitoring of behaviour, providing feedback on performance and information about health consequences) and a gamification design (i.e. points and rankings) will be included to improve the interest and incentive of this non-game programme (Table 2) (Item 6). These motivational approaches were chosen because of their known effect on physical fitness [53], physical activity [54] and satisfaction [55]. Moreover, parents will be told to encourage their children to perform the exercise programme in order to increase motivation.

A personal trainer with a BSc degree in Sport Sciences will develop all the sessions of this programme (Item 2, 14a and 14b). The personal trainer will record 18 exercise sessions and they will be uploaded in a private 
Table 2 Translation and operationalization of BCTs targeting behaviour determinants into BIT elements

\begin{tabular}{|c|c|c|c|c|}
\hline Determinant & BCT & Operationalization & BIT element & Workflow \\
\hline $\begin{array}{l}\text { Perceived behavioural control; } \\
\text { Autonomy; Planning; } \\
\text { knowledge/awareness }\end{array}$ & $\begin{array}{l}\text { Action planning and goal } \\
\text { setting (behaviour) }\end{array}$ & $\begin{array}{l}\text { Inform the participants about the phase of the } \\
\text { intervention and goals }\end{array}$ & $\begin{array}{l}\text { WhatsApp } \\
\text { group } \\
\text { message }\end{array}$ & $\begin{array}{l}\text { Every } 2 \text { weeks } \\
\text { (Sunday) }\end{array}$ \\
\hline $\begin{array}{l}\text { Perceived behavioural control; } \\
\text { Intentions; Competence; } \\
\text { Knowledge/awareness }\end{array}$ & $\begin{array}{l}\text { Provide instructions and } \\
\text { demonstrations on how to } \\
\text { perform the behaviour }\end{array}$ & $\begin{array}{l}\text { Give instructions and demonstrations about how to } \\
\text { perform the training session }\end{array}$ & $\begin{array}{l}\text { Videos with } \\
\text { exercise } \\
\text { proposals }\end{array}$ & $\begin{array}{l}\text { Every } 2 \text { weeks } \\
\text { (Sunday) }\end{array}$ \\
\hline $\begin{array}{l}\text { Perceived behavioural control; } \\
\text { Autonomy; Competence; } \\
\text { Knowledge/awareness }\end{array}$ & $\begin{array}{l}\text { Prompt self-monitoring of } \\
\text { behaviour }\end{array}$ & $\begin{array}{l}\text { Ask the participants to report the intervention } \\
\text { compliance }\end{array}$ & $\begin{array}{l}\text { WhatsApp } \\
\text { group } \\
\text { message }\end{array}$ & $\begin{array}{l}\text { Every } 2 \text { weeks } \\
\text { (Sunday) }\end{array}$ \\
\hline $\begin{array}{l}\text { Perceived behavioural control; } \\
\text { Relatedness; Competence; } \\
\text { Knoledge/awareness }\end{array}$ & $\begin{array}{l}\text { Provide feedback on } \\
\text { performance }\end{array}$ & $\begin{array}{l}\text { Inform the participants about their performance in } \\
\text { the main exercises (i.e. body mass-based squat, squat } \\
\text { jump and countermovement jump) }\end{array}$ & $\begin{array}{l}\text { WhatsApp } \\
\text { group } \\
\text { message or } \\
\text { video }\end{array}$ & $\begin{array}{l}\text { Every } 2 \text { weeks } \\
\text { (Friday) }\end{array}$ \\
\hline $\begin{array}{l}\text { Perceived behavioural control; } \\
\text { Attitude (beliefs); Knowledge/ } \\
\text { awareness }\end{array}$ & $\begin{array}{l}\text { Information about health } \\
\text { consequences }\end{array}$ & $\begin{array}{l}\text { Present press releases to emphasize the importance } \\
\text { of calcium and vitamin D for bone health }\end{array}$ & $\begin{array}{l}\text { WhatsApp } \\
\text { group } \\
\text { message }\end{array}$ & $\begin{array}{l}\text { At the } \\
\text { beginning of } \\
\text { each phase } \\
\text { (Sunday) }\end{array}$ \\
\hline
\end{tabular}

$B C T$ behaviour change technique, $B I T$ behaviour intervention technology

channel of the YouTube website. Each of them will be repeated over a 2 weeks period. The YouTube platform has been reported to be an educational tool for healthcare conditions among people coping with illness [56]. Every new session for the following 2 weeks will be shared through the WhatsApp group every 2 weeks. Finally, participants will perform the exercise programme individually or accompanied (i.e. with parents or friends) according to their preferences (Item 3) [57]. They will be required to record videos and send through the WhatsApp group in order to supervise the execution of the jumping exercises by the personal trainer. The exercise programme will be performed on a hard surface (Item 1) [58], and participants will be asked to report any pain or injuries at each stage of the intervention (Item 11).

\section{Frequency and volume}

Following the updated physical activity guidelines, children and adolescents should include bone-strengthening exercises as part of the daily physical activity on at least 3 days per week. Participants in the iBoneFIT study will perform the exercise programme three to 4 days per week (preferably on Mondays, Wednesdays and Fridays; or Mondays, Tuesdays, Thursdays and Fridays). If one training session is missed, the participant will be able to do it on a different day of the week, provided a minimum of $24 \mathrm{~h}$ of rest.

The total volume will be 7296 squat/jumps (2000 squats +5296 jumps). The doses will be composed of 136 sessions $(10-20 \mathrm{~min} / \mathrm{session})$ over 36 weeks. A full description of the training volume and its progression is shown in Table 3. In a recent 9-month RCT based on jumping activities with similar dosage we reached $70 \%$ of compliance (6216 jumps), and this was enough to improve bone outcomes in non-weight-bearing sport athletes [38]. Thus, the proposed volume of 7296 squat/ jumps is likely to elicit the same effect in paediatric cancer survivors.

\section{Periodisation}

Although Peitz et al. [59] did not find differences between no, linear and undulating periodisations in youth, iBoneFIT will implement a linear model based on the fact that variation in volume and/or impact loading within the programme phases may stimulate greater bone adaptions and reduce boredom and risk of overtraining [44]. The exercise programme will be divided in three phases of different durations and impact loadings (i.e. height reached in the different jumps). Each phase will be composed of levels with progressive increase in volume (i.e. repetitions, sets per day and sessions per week) as shown in Table 3 (Item 7b).

The phase 1 corresponds to the first 8 weeks of the exercise programme. Participants will perform body massbased squats and the volume will increase progressively by modifying the number of repetitions and sets per day. Paediatric cancer survivors may present reduced aBMD and muscular fitness [60], therefore jumping exercise prescription may not be safe. In this sense, body massbased squat was chosen in this phase following previous studies that observed positive effects on muscular fitness after an 8-week intervention [61, 62].

The phase 2 will last 12 weeks and participants will perform squat jumps. In this phase, the volume will increase progressively by modifying the number of repetitions, sets per day and sessions per week. Squat jump has been chosen as intermediary exercise before the use of countermovement jump since the jump height reached is lower and hence, ground reaction forces produced at the landing are lower [63]. Furthermore, squat 
Table 3 iBoneFIT study exercise programme periodisation

\begin{tabular}{|c|c|c|c|c|c|c|c|}
\hline Phase & Warm up ${ }^{a}$ & Exercise $^{b}$ & Level & Repetitions & $\begin{array}{l}\text { Sets a day } \\
\left(\text { Rest }^{\mathrm{C}}\right)\end{array}$ & Sessions a Week & Squats/Jumps a Week \\
\hline \multirow[t]{2}{*}{1} & RAMP & BM-based Squat & $1(1-4 w k)$ & 15 & 3 & 4 & 180 \\
\hline & & & $2(5-8 w k)$ & 20 & 4 & 4 & 320 \\
\hline Total phase 1 (8 wk) & & & & & & & 2000 \\
\hline \multirow[t]{3}{*}{2} & RAMP & SJ & 1 (9-12 wk) & 10 & 3 & 3 & 90 \\
\hline & & & $2(13-16 w k)$ & 15 & 3 & 4 & 180 \\
\hline & & & $3(17-20 w k)$ & 20 & 4 & 4 & 320 \\
\hline Total phase 2 (12 wk) & & & & & & & 2360 \\
\hline \multirow[t]{4}{*}{3} & RAMP & CMJ & 1 (21-24 wk) & 10 & 3 & 3 & 90 \\
\hline & & & $2(25-28 w k)$ & 12 & 3 & 4 & 144 \\
\hline & & & 3 (29-32 wk) & 15 & 3 & 4 & 180 \\
\hline & & & 4 (33-36 wk) & 20 & 4 & 4 & 320 \\
\hline Total phase 3 (16 wk) & & & & & & & 2936 \\
\hline Total intervention (36 wk) & & & & & & & 7296 \\
\hline
\end{tabular}

RAMP raise, activate, mobilise and potentiate, $B M$ body mass, $S J$ squat jump, $C M J$ countermovement jump

${ }^{a}$ Warm up will be focused on dynamic exercises with progressive intensity enhancing optimal core body temperature, motor unit excitability, kinesthetic awareness and ranges of motion

${ }^{b}$ Each exercise will be suggested to be performed at the pace of the personal trainer managing the session. If not, a self-paced performance will be recommend 'Phase 1 rest $=45 \mathrm{~s}$

Phases 2 and 3 rest $=1 \mathrm{~min}$

jump training reduces the degree of muscle slack on the push-off phase [64] which could supply a better execution of the countermovement jump afterwards.

The phase 3 will be the longest phase of the exercise programme with 16 weeks. Participants will perform countermovement jumps and the volume of this phase will be increased progressively by modifying the number of repetitions, sets per day and sessions per week. Countermovement jump will be chosen in this phase since it produces a huge force application $(\sim 400$ times body mass / second) and ground reaction forces $(\sim 5$ times body mass) in youth $[65,66]$. Countermovement jump has been previously reported to be valid and reliable in children [67].

\section{Session structure}

The structure of the exercise sessions will be: 1) warm up; 2) squat/jumps training; 3) cool down. Briefly, the warm ups will be based on RAMP methodology (i.e. raise, activate, mobilize and potentiate) in order to maximize middle-term performance of the main exercises (i.e. squat/jumps exercises) [68]. Eight exercises focused on the brace, squat, lunge or jump patterns will be included in this part of the session. Squat/jumps training will comprise body mass-based squats, squat jumps and countermovement jumps in phase 1 , phase 2 and phase 3, respectively. Finally, participants will perform a cool down including static stretching and relaxing exercises (Item 8).

\section{Control group}

Participants randomly allocated to the CG will receive information on the recommendations of calcium and vitamin D [69]. Educational leaflets and infographics based on the current recommendations [69] will be delivered to the participants at the beginning of the study (Item 10). After finishing the study, they will be offered the same online exercise programme.

\section{Outcomes}

The primary outcome of our study is bone health. The secondary outcomes include anthropometric measurements, body composition, physical fitness components, free-living physical activity, blood samples, calcium and vitamin D intake, health-related quality of life and mental health. Assessments will be conducted at baseline, repeated at post-test (i.e. after 2 weeks of intervention or control condition at most) and follow up (i.e. after 4 months of intervention or control condition). Participants will be assessed for the post-test and follow up following the order through which they will be tested at baseline, to avoid cofounding by time between baseline and the other assessments.

Data obtained on the assessments will be recorded on a paper print-out and entered into an Excel file for future statistical analysis. Questionnaires will be filled using Google Forms which allows us to record the data without hand-written management. In compliance with the Personal Information Protection Act, the names of all participants will not be disclosed, and an identifier 
number will be used to identify each participant. All participants will be informed that the clinical data obtained in the trial will be stored in a computer and will be handled with confidentiality.

\section{Primary outcome: bone health}

Dual-energy X-ray Absorptiometry (DXA)

A DXA (Hologic Series Discovery QDR, Bedford, MA, USA) will be used throughout the study to obtain BMC (g) and aBMD $\left(\mathrm{g} / \mathrm{cm}^{2}\right)$ for the hip, lumbar spine and total body less head. Furthermore, lean soft tissue mass (g), fat mass $(\mathrm{kg})$ and body fat percentage (\%) for the whole body will be obtained from total body scans. APEX software (version 4.0.2) will be used to analyse the scans following the recommendations for children and adolescents [70]. Equipment calibration, participant setting and scan analyses will be performed by the same researcher. DXA uses a minimal radiation (i.e. spending a day outside in the sunshine) and the effective dose for the scans in children has been set in 3-6 $\mu \mathrm{Sv}$ [71].

Hip Structural Analysis (HSA) HSA is a DXA-based software that analyses hip scans to estimate bone geometric properties of the proximal femur. This software analyses structural characteristics through the distribution of bone mineral mass in a line of pixels across the bone axis [72]. These geometric estimates in the proximal femur will be derived from: 1 ) the cross-sectional area $\left(\mathrm{mm}^{2}\right)$; 2) section modulus $\left(\mathrm{mm}^{3}\right)$; and 3) the crosssectional moment of inertia $\left(\mathrm{mm}^{4}\right)$. For these variables, the short-term coefficient of variation has been reported to be between 2.4 and $10.1 \%$ [73].

Trabecular Bone Score (TBS) TBS is a DXA-based software (iNsight version 3.0, Medimaps, Pessac, France) that indirectly assesses the state of trabecular microarchitecture in the lumbar spine. Based on experimental variograms of the projected DXA image, TBS evaluates the heterogeneity of the grey-levels pixels of the aBMD and higher heterogeneity implies worse trabecular connectivity [74]. Low values reported in this parameter have been associated with a higher fracture risk, and therefore it is considered an index of bone quality [75]. The shortterm coefficient of variation for TBS has been reported to be between 1.7 and $2.1 \%$ for spine aBMD in 92 individuals with repeated spine DXA scans performed within 28 days [76].

3D-DXA Modelling 3D-SHAPER is a DXA-based software (version 2.2, Galgo Medical, Barcelona, Spain) that derives 3D analyses from the hip DXA scans. Details of the model algorithm are published elsewhere [77]. Briefly, this software uses a 3D statistical shape and density of the proximal femur built from a database of quantitative computed tomography (QCT) scans of Caucasian population [77]. The 3D-SHAPER will assess bone parameters such as the cortex, the femoral shape and the trabecular macrostructure [78].

The cortex is segmented by fitting a mathematical function of the cortical thickness $(\mathrm{mm})$, cortical volumetric BMD (cortical vBMD, $\mathrm{mg} / \mathrm{cm}^{3}$ ), the location of the cortex, the density of surrounding tissues and the imaging blur to the density profile computed along the normal vector at each node of the proximal femur surface mesh [78]. In addition, the cortical surface BMD (cortical sBMD, mg/ $\mathrm{cm}^{2}$ ) is computed at each vertex of the femoral surface mesh, as the multiplication of the cortical thickness $(\mathrm{cm})$ by the cortical vBMD along its thickness [79]. Any increase in either cortical thickness or cortical vBMD will ensure an increase in cortical sBMD. Nevertheless, if cortical thickness and cortical vBMD vary in opposite ways, cortical sBMD will remain unchanged. All measurements will be computed over the total femur (i.e. the shaft, the intertrochanteric and the union of the neck) according to the trabecular, cortical and integral compartments.

Correlation coefficients between BMD computed by 3D-SHAPER and QCT of the total femur have been reported to be $0.86-0.95$, whereas the correlation coefficients of BMD computed by 3D-SHAPER with BMD computed by QCT have been reported to be 0.91 [77]. The short-term coefficients of variations of aBMD measurements have been reported to be $1.5,4.5,1.7$ and $1.5 \%$ for cortical thickness, trabecular vBMD, cortical vBMD and cortical sBMD, respectively [79].

\section{Secondary outcomes}

\section{Anthropometric measurement, body composition and somatic maturation}

Body mass $(\mathrm{kg})$ will be measured with an electronic scale (SECA 861, Hamburg, Germany) with an accuracy of $100 \mathrm{~g}$. Height $(\mathrm{cm})$ will be measured by using a precision stadiometer (SECA 225, Hamburg, Germany) to the nearest $0.1 \mathrm{~cm}$. Body mass index (BMI) will be calculated as body mass $(\mathrm{kg}) /$ height $\left(\mathrm{m}^{2}\right)$, and the participants will be classified into BMI categories according to sex- and age-specific cut offs [80].

In addition to DXA measurements, a bioimpedance scale (Tanita BC-418 MA; Amsterdam, The Netherlands; range: $2-200 \mathrm{~kg}$; precision: $0.1 \mathrm{~kg}$; body fat percentage increments: $0.1 \%$ ) will estimate the percentage of body fat of the participants. The assessment will be carried out in fasting state according to the manufacturer's instructions. Despite the measured error, bioelectrical impedance analysis will be used to assess body fat as it is considered a practical method in addition to DXA [81].

Somatic maturation will be assessed using the prediction of years from peak height velocity using validated algorithms for children [82]. 


\section{Physical fitness}

The ALPHA fitness test battery will be used to assess physical fitness. These field-based fitness tests have been shown to be valid, reliable and related to health in children and adolescents [83]. In brief, cardiorespiratory fitness will be assessed with the $20 \mathrm{~m}$ shuttle run test; muscular fitness will be assessed with the handgrip strength and standing long jump tests; and speed agility will be assessed with the $4 \times 10 \mathrm{~m}$ shuttle run test. All tests will be performed twice, and the best score will be retained, except $20 \mathrm{~m}$ shuttle run test.

Perceived physical fitness will be assessed by the International Fitness Scale (IFIS). The IFIS is a short, simple and self-administered scale that has been validated in children and adolescents $[84,85]$. This 5-item scale asks the participants about their physical fitness comparing with their colleagues.

\section{Physical activity and sedentarism}

Physical activity and sedentary behaviours will be objectively assessed at the baseline, post-intervention and follow-up measurements. Participants will wear a tri-axial accelerometer (ActiGraph GT3X, Pensacola, FL, USA) attached to the non-dominant wrist over seven consecutive days $(24 \mathrm{~h} /$ day $)$ and they will remove it only for waterbased activities (e.g. bathing or swimming). They will also have a diary in order to record the time when they go to bed, wake up and remove the device. Correlation coefficient between accelerometer measured metabolic energy equivalents and indirect calorimetry has been reported to be 0.65 [86], whilst correlation coefficient of accelerometer impact loading and ground reaction forces by force platforms has been reported to be 0.74 [87].

In addition, information on self-reported physical activity and sedentary behaviours will be obtained by the crosstranslated and adapted version of the Youth Activity Profile (YAP) questionnaire (available at: http://profith.ugr.es/ yap?lang=en). The YAP questionnaire was developed at the Iowa State University and validated in children [88]. This self-administered 7-day recall questionnaire collects data from items regarding physical activity in the school setting, physical activity out of the school setting, activity immediately after school, activity during the evening and activity during each weekend day. Moreover, the bone-specific physical activity questionnaire (BPAQ) will be used to assess the influence of historical physical activity (i.e. activities in which you have ever participated, and activities practiced in the last 12 months) on skeletal health. It has been reported that BPAQ is a valid instrument to account for the effects of previous physical activities on the skeleton [66].

\section{Calcium intake and vitamin $D$ status}

To correctly interpret bone health of the participants, an assessment of dietary intake of calcium will be completed at the baseline, post-intervention and followup measurements. A validated food-frequency questionnaire will be used to estimate calcium intake [89]. In addition to plasma 25-hydroxyvitamin D levels obtained from blood analyses (see blood samples section), a vitamin D questionnaire to assess the status of this prohormone will be implemented [90].

\section{Blood samples}

Fasting blood samples will be collected by venepuncture between 8:00 and 10:00 after an overnight fast. The methodology for shipment, preparation and collection of the blood samples was standardized among all participating hospitals. A set of parameters obtained from haematological and biochemical analyses will be available from the hospitals as part of the follow-up protocols.

\section{Health-related quality of life and mental health}

The Paediatric Quality of Life Inventory (PedsQL ${ }^{\text {тм }} 4.0$ Generic Core Scales) will be used to assess quality of life. PedsQL ${ }^{\mathrm{Tm}}$ is validated in paediatric cancer survivors and has been successfully used [91]. This 23-item scale assesses quality of life considering five domains of health (i.e. physical functioning, emotional functioning, psychosocial functioning, social functioning and school functioning). Results from our participants in all domains of PedsQL ${ }^{\mathrm{TM}}$ will be compared to published normative data [92].

Childhood anxiety will be assessed with the State-Trait Anxiety Inventory for Children (STAIC-T). This inventory has been extensively validated in Spanish children [93]. Depression will be measured with the Children Depression Inventory (CDI), which consists of 27 items that assesses 5 domains (interpersonal problems, ineffectiveness, negative mood, anhedonia and negative selfesteem) [94]. Rosenberg Self-Esteem scale will be used to assess self-esteem and has been validated with children and adolescents [95]. We will use the Positive Affect Schedule for children (PANAS-C) in order to measure both positive and negative affect [96]. The original PANAS-C reported appropriate values of internal consistency ( 0.86 for the positive affect and 0.82 for the negative affect). Happiness will be assessed by the Subjective Happiness Scale (SHS) whose Spanish version has shown appropriate test-retest reliability, internal consistency and convergent validity [97]. Dispositional optimism will be assessed with the Life Orientation Test-Revised (LOT-R) [98]. LOT-R is an instrument with good internal consistency ( 0.71 for the total score and of 0.64 and 0.77 for the optimism and pessimism, respectively) [99].

\section{Discussion}

The iBoneFIT study will examine the effect of an online $\mathrm{RCT}$ exercise programme on bone health in paediatric 
cancer survivors aged 6-18 years old. In addition, it will follow up the participants 4 months after the intervention to examine whether the effects remain. Finally, the iBoneFIT study will investigate whether the intervention affects body composition, physical fitness, physical activity, quality of life and mental health of paediatric cancer survivors.

Previous evidence shows a higher risk of delayed bone development, diminished muscle functioning, disability and compromised fundamental movement skill acquisition in children who have completed cancer treatment [79]. These side effects can also reduce motivation to be physically active and aggravate chronic health conditions in the short and long terms [100]. A recent longitudinal review showed that higher levels of muscular fitness in childhood and adolescent were associated with higher aBMD later in life [101]. Moreover, jumping interventions have shown improvements in both muscular fitness and bone health $[38,39,102]$. In this regard, Vlachopoulos et al. [39] reported an increase in physical fitness (3.7-7.9\%) and BMC at TBLH and legs (4.2$12.7 \%)$ in non-osteogenic sports. Additionally, Vlachopoulos et al. [38] showed that a 9-month plyometric training improved LS BMC (4.6\%) and femoral neck BMC (6-9.8\%) in non-osteogenic sports. Another study carried out by Mackelvie et al. [102] suggested that jump training was associated with increases in femoral neck, lumbar spine and total body aBMD $(\sim 2 \%)$ in prepubertal boys and may delay the onset of osteoporosis later in life. The Exercise Guidelines for Cancer Survivors recommend avoiding movements that place excessively high load on fragile skeletal sites [43]. Thus, our intervention aims to improve muscular strength before implementing mechanical loading through jumping exercises.

Several studies highlight that exercise interventions delivered during cancer treatment are not successful in improving bone health nor other factors such as health-related quality of life [40, 42], suggesting a new approach focusing on post treatment phase is needed. Furthermore, following the study of McKay et al. [36], the exercise programme should be effective, possible to perform at any place, short in duration, inexpensive and simple to administer. iBoneFIT has been designed to meet all these requirements. The exercise programme will be delivered online and using social media which also guarantees social distancing nowadays. Some international physical activity interventions based on online and app-based approaches have shown promising results, indicating the suitability of this technology to influence health behaviours [103, 104]. Therefore, analysing the effect of this exercise programme in paediatric cancer survivors is of scientific interest.

iBoneFIT represents a golden opportunity to analyse for the first time the effect of a simple, feasible, inexpensive and short duration exercise programme on bone health in paediatric cancer survivors. This study will target this population in high risk of low bone mass, using an enjoyable intervention and cutting-edge technologies (i.e. DXA and tri-axial accelerometers) to assess its effectiveness. If successful, this 9-month online exercise program will likely encourage paediatric cancer survivors to be physically active or even engage in a sport, providing an opportunity to decrease chronic health conditions in the short and long terms [6]. Finally, iBoneFIT will substantially contribute to the existing knowledge of how physical activity affects quality of life and mental health in this population. The long-term medical and psychological effects of childhood cancer or its treatment may negatively affect social functioning such as school attendance, obtaining employment and even social activities [100]. Therefore, their quality of life and mental health are important concerns, and efforts have to be made to improve it, which will have an important societal and economic impact.

\section{Abbreviations}

BMD: Bone mineral density; BMC: Bone mineral content; aBMD: Areal bone mineral density; $\vee B M D$ : Volumetric bone mineral density;

sBMD: Surface bone mineral density; RCT: Randomized controlled trial; IG: Intervention group; CG: Control group; CERT: Consensus on exercise reporting template; BCT: Behaviour change techniques; BIT: Behaviour intervention technology; DXA: Dual-energy x-ray absorptiometry; HSA: Hip structural analysis; TBS: Trabecular bone score;

BIA: Bioimpedance analysis; IFIS: International fitness scale; YAP-S: Youth activity profile-Spain; BPAQ: Bone-specific physical activity questionnaire; PedsQL: Paediatric quality of life inventory; STAIC-T: State-trait anxiety inventory for children; CDI: Children depression inventory; PANAS-C: Positive affect schedule for children; SHS: Subjective happiness scale; LOT-R: Life orientation testrevised

\section{Acknowledgments}

The authors gratefully acknowledge the 'Virgen de las Nieves' (Granada) and 'Reina Sofía' (Córdoba) for their help to run the study. We are grateful to Ms. Ana Yara Postigo-Fuentes for her assistance with the English language.

\section{Authors' contributions}

LGM (principal investigator), EUG, FBO, JRR, IL and VMV contributed to the draft of the project. JJGC and EUG wrote the initial draft of the manuscript under the supervision of LGM and DV. The recruitment will be performed by MJS, MJOA, MEM, AIB, FJLC, JFPG and MCVG. The analysis and interpretation of the data obtained will be supported by FBO, JRR, IL, VMV, FJLC, DV, MAM and MMT. All authors have read and agreed to the published version of the manuscript.

\section{Funding}

The iBoneFIT project is funded by a fellowship from "la Caixa" Foundation (ID 100010434). The fellowship code is LCF/BQ/PR19/11700007. This study has been partially supported by the University of Granada, Plan Propio de Investigación 2016, Excellence actions: Units of Excellence; Unit of Excellence on Exercise and Health (UCEES), and by the Junta de Andalucía, Consejería de Conocimiento, Investigación y Universidades and European Regional Development Fund (ERDF), ref. SOMM17/6107/UGR. The funders had no role in the design of this study, in the collection, analyses or interpretation of the data, in the writing of the manuscript or in the decision to submit the manuscript for publication. 


\section{Availability of data and materials}

The data that will be generated and analysed during the current study is not publicly available due to the sensitivity of the collected data. The data are available from the corresponding author upon reasonable request.

\section{Ethics approval and consent to participate}

This study will be performed following the ethical guidelines of the Declaration of Helsinki, last modified in 2013. This study has been checked and approved by the Ethics Committee on Human Research of Regional Government of Andalusia (Reference: 4500, December 2019). All participants will sign the informed consent before their participation in the study.

\section{Consent for publication}

Not applicable.

\section{Competing interests}

L.G.M. is an Associate Editor of BMC Public Health.

\section{Author details}

"PROFITH "PROmoting FITness and Health through Physical Activity" Research Group, Sport and Health University Research Institute (iMUDS), Department of Physical Education and Sports, Faculty of Sport Sciences, University of Granada, 18071 Granada, Spain. ${ }^{2}$ Andalusian School of Health (EASP), Granada, Spain. ${ }^{3}$ Instituto de Investigación Biosanitaria Ibs.GRANADA, Granada, Spain. ${ }^{4} \mathrm{CIBER}$ of Epidemiology and Public Health (CIBERESP), Madrid, Spain. ${ }^{5}$ Department of Preventive Medicine and Public Health, University of Granada, Granada, Spain. ${ }^{6}$ Servicio de Pediatría y Oncohematología Pediátricas, Hospital Universitario Virgen de las Nieves, Granada, Spain. 'Pediatric Oncology Unit, Department of Pediatrics, Reina Sofia University Hospital, Córdoba, Spain. ${ }^{8}$ Maimonides Institute for Research in Biomedicine of Cordoba (IMIBIC), Córdoba, Spain. ${ }^{9}$ Hospital Infantil Universitario Niño Jesús, Madrid, Spain. ${ }^{10} \mathrm{CIBEROBN}$, (Physiopathology of Obesity and Nutrition) Institute of Health Carlos III (ISCIII), 28029 Madrid, Spain. ${ }^{11}$ Department of Specific Didactics, Faculty of Education, University of Córdoba, 14071 Córdoba, Spain. ${ }^{12}$ Institute for Innovation and Sustainable Development in Food Chain (IS-FOOD), Navarra's Health Research Institute (IdiSNA), Department of Health Sciences, Public University of Navarra, Calle Tajonar 22, 31006 Pamplona, Navarra, Spain. ${ }^{13}$ Universidad de Castilla-La Mancha, Health and Social Research Center, Cuenca, Spain. ${ }^{14}$ Faculty of Health Sciences, Universidad Autónoma de Chile, Talca, Chile. ${ }^{15}$ Children's Health and Exercise Research Centre, Sport and Health Sciences, University of Exeter, Exeter, UK. ${ }^{16}$ Biohealth Research Institute in Granada (ibs.GRANADA), E-18012 Granada, Spain. ${ }^{17}$ Department of Physiotherapy, University of Granada, E-18016 Granada, Spain. ${ }^{18 "}$ "Cuídate" Support Unit for Oncology Patients (UAPO), Sport and Health University Research Institute (iMUDS), E-18016 Granada, Spain. ${ }^{19}$ Bone Metabolic Unit, Endocrinology and Nutrition Division, Hospital Universitario San Cecilio, Instituto de Investigación Biosanitaria de Granada (Ibs.GRANADA), Granada, Spain. ${ }^{20}$ CIBERFES, Instituto de Salud Carlos III, Madrid, Spain. ${ }^{21}$ Department of Medicine, Universidad de Granada, Granada, Spain

Received: 23 July 2020 Accepted: 14 September 2020 Published online: 08 October 2020

\section{References}

1. Steliarova-Foucher E, Fidler MM, Colombet M, Lacour B, Kaatsch P, Piñeros $M$, et al. Changing geographical patterns and trends in cancer incidence in children and adolescents in Europe, 1991-2010 (automated childhood Cancer information system): a population-based study. Lancet Oncol. 2018; 19(9):1159-69.

2. Gatta G, Botta L, Rossi S, Aareleid T, Bielska-Lasota M, Clavel J, et al. Childhood cancer survival in Europe 1999-2007: results of EUROCARE-5-a population-based study. Lancet Oncol. 2014;15(1):35-47.

3. Trama A, Botta L, Foschi R, Ferrari A, Stiller C, Desandes E, et al. Survival of European adolescents and young adults diagnosed with cancer in 2000-07: population-based data from EUROCARE-5. Lancet Oncol. 2016;17(7):896-906 Available from: http://dx.doi.org/10.1c016/S1470-2045(16)00162-5.

4. Hudson MM, Mertens AC, Yasui Y, Hobbie W, Chen H, Gurney JG, et al. Health status of adult Long-term survivors of childhood Cancer: a report from the childhood Cancer survivor study. J Am Med Assoc. 2003;290(12):1583-92.
5. Mertens AC, Yasui Y, Neglia JP, Potter JD, Nesbit J, Ruccione K, et al. Late mortality experience in five-year survivors of childhood and adolescent cancer: the childhood Cancer survivor study. J Clin Oncol. 2001;19(13):3163-72.

6. Oeffinger KC, Mertens AC, Sklar CA, Kawashima T, Hudson MM, Meadows AT, et al. Chronic health conditions in adult survivors of childhood cancer. N Engl J Med. 2006;355(15):1572-82.

7. Langeveld NE, Stam H, Grootenhuis MA, Last BF. Quality of life in young adult survivors of childhood cancer. Support Care Cancer. 2002;10(8):579-600.

8. Eiser $C$. Examining the psychological consequences of surviving childhood Cancer: systematic review as a research method in pediatric psychology. J Pediatr Psychol. 2000;25(6):449-60.

9. Rose SR, Horne VE, Howell J, Lawson SA, Rutter MM, Trotman GE, et al. Late endocrine effects of childhood cancer. Nat Rev Endocrinol 2016;12(6):319_ 336. https://doi.org/10.1038/nrendo.2016.45

10. Marcucci G, Beltrami G, Tamburini A, Body JJ, Confavreux CB, Hadji P, et al. Bone health in childhood cancer : review of the literature and recommendations for the management of bone health in childhood cancer survivors. Role plasma microseminoprotein-beta prostate cancer. Ann Oncol. 2019;30(6):908-20. https://doi.org/10.1093/annonc/mdz120.

11. van Leeuwen BL, Kamps WA, Jansen HWB, Hoekstra HJ. The effect of chemotherapy on the growing skeleton. Cancer Treat Rev. 2000;26:363-76.

12. Wilson $\mathrm{CL}$, Dilley $\mathrm{K}$, Ness KK, Leisenring WL, Sklar CA, Kaste SC, et al. Fractures among long-term survivors of childhood cancer: a report from the childhood Cancer survivor study. Cancer. 2012;118(23):5920-8.

13. Halton J, Gaboury I, Grant R, Alos N, Cummings EA, Matzinger M, et al. Advanced vertebral fracture among newly diagnosed children with acute lymphoblastic leukemia: results of the Canadian steroid-associated osteoporosis in the pediatric population (STOPP) research program. J Bone Miner Res. 2009;24(7):1326-34.

14. Van Der Sluis IM, Van Den Heuvel-Eibrink MM, Hählen K, Krenning EP, De Muinck K-SSMPF. Altered bone mineral density and body composition, and increased fracture risk in childhood acute lymphoblastic leukemia. J Pediatr. 2002;141(2):204-10.

15. Alos N, Grant RM, Ramsay T, Halton J, Cummings EA, Miettunen PM, et al. High incidence of vertebral fractures in children with acute lymphoblastic leukemia 12 months after the initiation of therapy. J Clin Oncol. 2012;30(22):2760-7.

16. Wren TAL, Kalkwarf HJ, Zemel BS, Lappe JM, Oberfield S, Shepherd JA, et al. Longitudinal tracking of dual-energy X-ray absorptiometry bone measures over 6 years in children and adolescents: Persistence of low bone mass to maturity. J Pediatr. 2014;164(6):1280-1285.e2. https://doi.org/10.1016/j.jpeds.2013.12.040.

17. Clark EM, Ness AR, Bishop NJ, Tobias JH. Association between bone mass and fractures in children: a prospective cohort study. J Bone Miner Res. 2006;21(9):1489-95.

18. Wilson $\mathrm{CL}$, Ness KK. Bone mineral density deficits and fractures in survivors of childhood cancer. Curr Osteoporos Rep. 2013;11(4):329-37.

19. Rizzoli R, Bianchi ML, Garabédian M, McKay HA, Moreno LA. Maximizing bone mineral mass gain during growth for the prevention of fractures in the adolescents and the elderly. Bone. 2010;46(2):294-305. https://doi.org/ 10.1016/j.bone.2009.10.005

20. Baxter-Jones ADG, Faulkner RA, Forwood MR, Mirwald RL, Bailey DA. Bone mineral accrual from 8 to 30 years of age: an estimation of peak bone mass. J Bone Miner Res. 2011;26(8):1729-39.

21. Weaver CM, Gordon CM, Janz KF, Kalkwarf HJ, Lappe JM, Lewis R, et al. The National Osteoporosis Foundation's position statement on peak bone mass development and lifestyle factors: a systematic review and implementation recommendations. Osteoporos Int. 2016;27(4):1281-386.

22. Vlachopoulos D, Barker AR, Ubago-Guisado E, Fatouros IG, Knapp KM, Williams CA, et al. Longitudinal adaptations of bone mass, geometry, and metabolism in adolescent male athletes: the PRO-BONE study. J Bone Miner Res. 2017;32(11):2269-77.

23. Ubago-Guisado E, Martinez-Rodriguez A, Gallardo L, Sánchez-Sánchez J. Bone mass in girls according to their BMI, VO2 max, hours and years of practice. Eur J Sport Sci. 2016;16(8):1176-86.

24. Ubago-Guisado E, Vlachopoulos D, Barker AR, Christoffersen T, Metcalf B, Gracia-Marco L. Effect of maturational timing on bone health in male adolescent athletes engaged in different sports: the PRO-BONE study. J Sci Med Sport. 2020;22(3):253-258. https://doi.org/10.1016/j.jsams.2018.08.009.

25. Gracia-Marco L, Vicente-Rodríguez G, Casajús JA, Molnar D, Castillo MJ, Moreno LA. Effect of fitness and physical activity on bone mass in adolescents: the HELENA study. Eur J Appl Physiol. 2011;111(11):2671-80. 
26. Ubago-Guisado E, Vlachopoulos D, Fatouros IG, Deli CK, Leontsini D, Moreno LA, et al. Longitudinal determinants of 12-month changes on bone health in adolescent male athletes. Arch Osteoporos. 2018;13(1):106. https:// doi.org/10.1007/s11657-018-0519-4.

27. Ubago-Guisado E, Sánchez-Sánchez J, Vila-Maldonado S, Gallardo L. Effects of Zumba ${ }^{\oplus}$ and aquagym on bone mass in inactive middle-aged women. Med. 2019;55(1):1-10.

28. Yang X, Zhai Y, Zhang J, Chen JY, Liu D, Zhao WH. Combined effects of physical activity and calcium on bone health in children and adolescents: a systematic review of randomized controlled trials. World J Pediatr. 2020; 9(0123456789). https://doi.org/10.1007/s12519-019-00330-7.

29. Valtuena J, Gracia-Marco L, Vicente-Rodríguez G, González-Gross M, Huybrechts I, Rey-López JP, et al. Vitamin D status and physical activity interact to improve bone mass in adolescents. The HELENA Study. Osteoporos Int. 2012;23(8):2227-37.

30. Kaste SC, Qi A, Smith K, Surprise H, Lovorn E, Boyett J, et al. Calcium and Cholecalciferol supplementation provides no added benefit to nutritional Counselin to improve bone mineral density in survivors of childhood acute lymphoblastic leukemia (ALL). Pediatr Blood Cancer. 2014;61:885-93.

31. Boreham CAG, McKay HA. Physical activity in childhood and bone health. Br J Sports Med. 2011;45(11):877-9.

32. Vicente-Rodríguez G. How does exercise affect bone development during growth? Sport Med. 2006;36(7):561-9.

33. Goodman CA, Hornberger TA, Robling AG. Bone and skeletal muscle: key players in mechanotransduction and potential overlapping mechanisms. Bone 2015;80:24-36. https://doi.org/10.1016/j.bone.2015.04.014.

34. Frost HM. Bone's Mechanostat: a 2003 update. Anat Rec Part A Discov Mol Cell Evol Biol. 2003;275(2):1081-101.

35. Gómez-Bruton A, Matute-Llorente Á, González-Agüero A, Casajús JA, Vicente-Rodríguez G. Plyometric exercise and bone health in children and adolescents: a systematic review. World J Pediatr. 2017;13(2):112-21.

36. McKay HA, MacLean L, Petit M, MacKelvie-O'Brien K, Janssen P, Beck T, et al. "Bounce at the bell": a novel program of short bouts of exercise improves proximal femur bone mass in early pubertal children. Br J Sports Med. 2005; 39(8):521-6

37. MacKelvie KJ, McKay HA, Khan KM, Crocker PRE. A school-based exercise intervention augments bone mineral accrual in early pubertal girls. J Pediatr. 2001;139(4):501-8.

38. Vlachopoulos D, Barker AR, Ubago-Guisado E, Williams CA, Gracia-Marco L. A 9-month jumping intervention to improve bone geometry in adolescent male athletes. Med Sci Sports Exerc. 2018;50(12):2544-54.

39. Vlachopoulos D, Barker AR, Ubago-Guisado E, Williams CA, Gracia-Marco L. The effect of a high-impact jumping intervention on bone mass, bone stiffness and fitness parameters in adolescent athletes. Arch Osteoporos. 2018;13(1):128. https://doi.org/10.1007/s11657-018-0543-4.

40. Hartman A, Winkel M, van Beek R, de Muinck Keizer-Shrama SMP, Kemper HC, Hop WC, et al. A randomized trial investigating an exercise program to prevent reduction of bone mineral density and impairment of motor performance during treatment for childhood acute lymphoblastic leukemia. Pediatr Blood Cancer. 2009;53:64-71.

41. Mogil RJ, Kaste SC, Ferry RJ, Hudson MM, Mulrooney DA, Howell CR, et al. Effect of low-magnitude, high-frequency mechanical stimulation on BMD among young childhood cancer survivors a randomized clinical trial. JAMA Oncol. 2016;2(7):908-14.

42. Cox CL, Zhu L, Kaste SC, Srivastava K, Barnes L, Nathan PC, et al. Modifying bone mineral density, physical function, and quality of life in children with acute lymphoblastic leukemia. Pediatr Blood Cancer. 2018;65(4):1-8.

43. Campbell KL, Winters-Stone KM, Wiskemann J, May AM, Schwartz AL, Courneya KS, et al. Exercise guidelines for Cancer survivors: consensus statement from international multidisciplinary roundtable. Med Sci Sports Exerc. 2019;51(11):2375-90. http://www.ncbi.n/m.nih.gov/pubmed/31626055.

44. Hayes SC, Newton RU, Spence RR, Galvão DA. The exercise and sports science Australia position statement: exercise medicine in cancer management. J Sci Med Sport. 2019;22(11):1175-99. https://doi.org/10.1016/ j.jsams.2019.05.003.

45. Chan A, Tetzlaff JM, Altman DG, Laupacis A, Gøtzsche PC, Hro A, et al. SPIRIT 2013 statement: defining standard protocol items for clinical trials. Ann Intern Med. 2013;158(3):200-7.

46. Slade SC, Dionne CE, Underwood M, Buchbinder R. Consensus on exercise reporting template (CERT): explanation and elaboration statement. $\mathrm{Br}$ J Sports Med. 2016;50(23):1428-37.
47. Behm DG, Young JD, Whitten JHD, Reid JC, Quigley PJ, Low J, et al. Effectiveness of traditional strength vs. power training on muscle strength, power and speed with youth: A systematic review and meta-analysis. Front Physiol. 2017:8:423. https://doi.org/10.3389/fphys.2017.00423.

48. Weeks BK, Young CM, Beck BR. Eight months of regular in-school jumping improves indices of bone strength in adolescent boys and girls: the POWER PE study. J Bone Miner Res. 2008;23(7):1002-11.

49. Kenkre JS, Bassett JHD. The bone remodelling cycle. Ann Clin Biochem. 2018;55(3):308-27

50. Courteix D, Jaffré C, Lespessailles E, Benhamou L. Cumulative effects of calcium supplementation and physical activity on bone accretion in premenarchal children: a double-blind randomised placebo-controlled trial. Int J Sports Med. 2005;26(5):332-8.

51. Maher CA, Lewis LK, Ferrar K, Marshall S, De Bourdeaudhuij I, Vandelanotte $C$. Are health behavior change interventions that use online social networks effective? A systematic review. J Med Internet Res. 2014;16(2):1-13.

52. Ahmed OH, Carmody S, Walker LJ, Ahmad I. The need for speed! 10 ways that WhatsApp and instant messaging can enhance communication ( and clinical care ) in sport and exercise medicine. Br J Sports Med. 2020;0(0): 2019-20.

53. Muntaner-Mas A, Vidal-Conti J, Borràs PA, Ortega FB, Palou P. Effects of a Whatsapp-delivered physical activity intervention to enhance health-related physical fitness components and cardiovascular disease risk factors in older adults. J Sports Med Phys Fitness. 2017;57(1-2):90-102.

54. Direito A, Walsh D, Hinbarji M, Albatal R, Tooley M, Whittaker $R$, et al. Using the intervention mapping and behavioral intervention technology frameworks: development of an mHealth intervention for physical activity and sedentary behavior change. Heal Educ Behav. 2018;45(3):331-48.

55. Sailer M, Hense JU, Mayr SK, Mandl H. How gamification motivates: An experimental study of the effects of specific game design elements on psychological need satisfaction. Comput Human Behav. 2017;69:371-380. https://doi.org/10.1016/j.chb.2016.12.033.

56. Madathil KC, Rivera-Rodriguez AJ, Greenstein JS, Gramopadhye AK. Healthcare information on YouTube: a systematic review. Health Informatics J. 2015;21(3):173-94.

57. Ross WL, Le A, Zheng DJ, Mitchell HR, Rotatori J, Li F, et al. Physical activity barriers, preferences, and beliefs in childhood cancer patients. Support Care Cancer. 2018;26(7):2177-84.

58. Ubago-Guisado E, García-Unanue J, López-Fernández J, Sánchez-Sánchez J, Gallardo L. Association of different types of playing surfaces with bone mass in growing girls. J Sports Sci. 2017;35(15):1484-92.

59. Peitz M, Behringer M, Granacher U. Correction: A systematic review on the effects of resistance and plyometric training on physical fitness in youth-What do comparative studies tell us? PLoS ONE. 2018;13(10):e0205525. https://doi. org/10.1371/journal.pone.0205525 Vol. 13, PLoS ONE. 2018. 1-44 p.

60. Long TM, Rath SR, Maroni TD, Wallman KE, Atkinson HC, Gottardo NG, et al. Fitness, body composition and vascular health in adolescent and young adult survivors of paediatric brain cancer and cranial radiotherapy. Int J Adolesc Med Health. 2017:1-13.

61. Takai $Y$, Fukunaga $Y$, Fujita E, Mori H, Yoshimoto T, Yamamoto M, et al. Effects of body mass-based squat training in adolescent boy. J Sport Sci Med. 2013;12(1):60-5.

62. Yoshimoto T, Takai Y, Fukunaga Y, Fujita E, Yamamoto M, Kanahisa H. Effects of school-based squat training in adolescent girls. J Sports Med Phys Fitness. 2016;56(6):678-83.

63. Bobbert MF, Casius LJR. Is the effect of a countermovement on jump height due to active state development? Med Sci Sports Exerc. 2005;37(3):440-6.

64. Van Hooren B, Zolotarjova J. The difference between countermovement and squat jump performances: a review of underlying mechanisms with practical applicactions. J Strength Cond Res. 2017;31(7):2011-20.

65. McKay H, Tsang G, Heinonen A, MacKelvie K, Sanderson D, Khan KM. Ground reaction forces associated with an effective elementary school based jumping intervention. Br J Sports Med. 2005;39(1):10-4.

66. Weeks BK, Beck BR. The BPAQ: a bone-specific physical activity assessment instrument. Osteoporos Int. 2008;1567-77.

67. Martín Acero R, Fernández-del Olmo M, Andrés Sánchez J, Luis Otero X, Aguado X, Rodríguez FA. Reliability of squat and countermovement jump tests in children 6 to 8 years of age. Pediatr Exerc Sci. 2011;23(1):151-60.

68. Jeffreys I. The Warm-Up: Maximize Performance and Improve Long-Term Athletic Development. Human Kinetics, editor; 2018. p. 216. 
69. McCullough ML, Robertson AS, Rodriguez C, Jacobs EJ, Chao A, Jonas C, et al. Calcium, vitamin D, dairy products, and risk of colorectal cancer in the Cancer prevention study II nutrition cohort (United States). Cancer Causes Control. 2003:14(1):1-12.

70. Crabtree NJ, Arabi A, Bachrach LK, Fewtrell M, El-Hajj Fuleihan G, Kecskemethy $\mathrm{HH}$, et al. Dual-energy $\mathrm{x}$-ray absorptiometry interpretation and reporting in children and adolescents: the revised 2013 ISCD pediatric official positions. J Clin Densitom. 2014;17(2):225-42.

71. Thomas S, Kalkwarf H, Buckley D, Heubi J. Effective dose of dual-energy Xray absorptiometry scans in children as a function of age. J Clin Densitom. 2005;8(4):415-22. http://elibrary.johnsonu.edu:2048/login?url=https://search proquest.com/docview/1637643243?accountid=34777\%0Ahttp://resolver. ebscohost.com/openurl.

72. Beck TJ, Ruff CB, Warden KE, Mebe SWW, Rao GU. Predicting femoral neck strength from bone mineral data: A structural approach. Invest Radiol. 1990; 25(1):6-18.

73. Khoo BCC, Beck TJ, Qiao QH, Parakh P, Semanick L, Prince RL, et al. In vivo short-term precision of hip structure analysis variables in comparison with bone mineral density using paired dual-energy $X$-ray absorptiometry scans from multi-center clinical trials. Bone. 2005;37(1):112-21.

74. Pothuaud L, Barthe N, Krieg MA, Mehsen N, Carceller P, Hans D. Evaluation of the potential use of trabecular bone score to complement bone mineral density in the diagnosis of osteoporosis: a preliminary spine BMD-matched, case-control study. J Clin Densitom 2009;12(2):170-176. https://doi.org/10. 1016/j.jocd.2008.11.006

75. Hans D, Goertzen AL, Krieg MA, Leslie WD. Bone microarchitecture assessed by TBS predicts osteoporotic fractures independent of bone density: the Manitoba study. J Bone Miner Res. 2011;26(11):2762-9.

76. Silva BC, Leslie WD, Resch H, Lamy O, Lesnyak O, Binkley N, et al. Trabecular bone score: a noninvasive analytical method based upon the DXA image. J Bone Miner Res. 2014;29(3):518-30.

77. Humbert L, Martelli Y, Fonolla R, Steghofer M, DI Gregorio S, Malouf J, et al. 3DDXA: assessing the femoral shape, the trabecular macrostructure and the cortex in 3D from DXA images. IEEE Trans Med Imaging. 2017;36(1):27-39.

78. Humbert L, Hazrati Marangalou J, Del Río Barquero LM, Van Lenthe GH, Van Rietbergen B. Technical note: cortical thickness and density estimation from clinical CT using a prior thickness-density relationship. Med Phys. 2016;43(4): 1945-54.

79. Winzenrieth R, Humbert L, Di Gregorio S, Bonel E, García M, Del Rio L. Effects of osteoporosis drug treatments on cortical and trabecular bone in the femur using DXA-based 3D modeling. Osteoporos Int. 2018;29(10):2323-33.

80. Cole TJ, Lobstein T. Extended international (IOTF) body mass index cut-offs for thinness, overweight and obesity. Pediatr Obes. 2012;7(4):284-94.

81. Talma H, Chinapaw MJM, Bakker B, Hirasing RA, Terwee CB, Altenburg TM. Obesity Diagnostic / Methodology Bioelectrical impedance analysis to estimate body composition in children and adolescents: a systematic review and evidence appraisal of validity, responsiveness, reliability and measurement error; 2013. p. 895-905.

82. Moore SA, McKay HA, Macdonald H, Nettlefold L, Baxter-Jones ADG, Cameron N, et al. Enhancing a somatic maturity prediction model. Med Sci Sports Exerc. 2015;47(8):1755-64.

83. Ruiz JR, Castro-piñero J, España-romero V, Artero EG, Ortega FB, Cuenca $\mathrm{MM}$, et al. Field-based fitness assessment in young people: the ALPHA health-related fi tness test battery for children and adolescents. Br J Sports Med. 2011:518-24.

84. Sánchez-López M, Martínez-Vizcaíno V, García-Hermoso A, Jiménez-Pavón D, Ortega FB. Construct validity and test-retest reliability of the international fitness scale (IFIS) in Spanish children aged 9-12 years. Scand J Med Sci Sport. 2015;25(4):543-51.

85. Ortega FB, Ruiz JR, España-Romero V, Vicente-Rodriguez G, Martínez-Gómez $D$, Manios $Y$, et al. The international fitness scale (IFIS): usefulness of selfreported fitness in youth. Int J Epidemiol. 2011;40(3):701-11.

86. Kozey SL, Lyden K, Howe CA, Staudenmayer JW, Freedson PS Accelerometer output and MET values of common physical activities. Med Sci Sports Exerc. 2010;42(9):1776-84

87. Rowlands A V., Stiles VH. Accelerometer counts and raw acceleration output in relation to mechanical loading. J Biomech. 2012;45(3):448-454. https:// doi.org/10.1016/j.jbiomech.2011.12.006.

88. Saint-maurice PF, Welk GJ. Web-based assessments of physical activity in youth: considerations for design and scale calibration corresponding author. J Med Internet Res. 2014;16:1-15.
89. Julián-Almárcegui C, Huybrechts I, Bruton AG, Llorente ÁM, Agüero AG, Cabello $A G$, et al. Validity of a food-frequency questionnaire for estimating calcium intake in adolescent swimmers. Nutr Hosp. 2015;32(4):1773-9.

90. Bolek-berquist J, Elliott ME, Gangnon RE, Gemar D, Lawrence SJ, Hansen KE. Use of a questionnaire to assess vitamin D status in Young adults. Public Health Nutr. 2009;12(2):236-43.

91. Shin H, Bartlett R, Gagne JC De. Journal of pediatric nursing health-related quality of life among survivors of Cancer in adolescence : an integrative literature review. J Pediatr Nurs. 2019;44:97-106. https://doi.org/10.1016/j. pedn.2018.11.009.

92. Varni J, Seid M, Kurtin P. The PedsQL 4.0 as a Pediatric Population Health Measure: Feasibility, Reliability, and Validity. Ambul Med Care. 2001;3(6):800-12.

93. Rodrigo G, Lusiardo M. Spanish version of the revised children's manifest anxiety scale in Uruguay: reliability and concurrent validity. Psychol Rep. 1989:55:11600.

94. Kovacs M. The Children's depression inventory (CDI); 1992.

95. Kinen MMÄ, Lindberg N, Komulainen E, Aalberg V, Marttunen M. Psychological well-being in adolescents with excess weight, vol. 7; 2014

96. Sandin B, Chorot P, Valiente RM. The PANAS Scales of Positive and Negative Affect : Factor Analytic Validation and Cross-cultural Convergence; 1999.

97. Extremera N, Ferna P. The Subjective Happiness Scale : Translation and Preliminary Psychometric Evaluation of a Spanish Version; 2014. p. 473-81.

98. Scheier MF, Carver CS, Bridges MW. Distinguishing optimism from neuroticism (and trait anxiety, self-mastery, and self-esteem): a reevaluation of the life orientation test. J Pers Soc Psychol. 1994;67(6):1063-78.

99. Gustems-Carnicer J, Calderón C, Forn Santacana M. Propiedades psicométricas del Life Orientation Test (LOT-R) y su relación con el bienestar psicológico y el progreso académico en estudiantes universitarios. Rev Latinoam Psicol 2017;49(1):19-27. https://doi.org/10.1016/j.rlp.2016.05.001.

100. Ness KK, Mertens AC, Hudson MM, Wall MM, Leisenring WM, Oeffinger $K C$, et al. Limitations on physical performance and daily activities among long-term survivors of childhood cancer. Ann Intern Med. 2005; 143(9):639-48.

101. García-Hermoso A, Ramírez-Campillo R, Izquierdo M. Is muscular fitness associated with future health benefits in children and adolescents? A systematic review and meta-analysis of longitudinal studies. Sport Med. 2019:49(7):1079-1094. https://doi.org/10.1007/s40279-019-01098-6.

102. Mackelvie KJ, McKay HA, Petit MA, Moran O, Khan KM. Bone mineral response to a 7-month randomized controlled, school-based jumping intervention in 121 prepubertal boys: associations with ethnicity and body mass index. J Bone Miner Res. 2002;17(5):834-44.

103. Patel MS, Benjamin EJ, Volpp KG, Fox CS, Small DS, Massaro JM, et al. Effect of a game-based intervention designed to enhance social incentives to increase physical activity among families: the BE FIT randomized clinical trial. JAMA Intern Med. 2017;177(11):1586-93.

104. Ganesan AN, Louise J, Horsfall M, Bilsborough SA, Hendriks J, McGavigan $A D$, et al. International Mobile-health intervention on physical activity, sitting, and weight: the Stepathlon cardiovascular health study. J Am Coll Cardiol. 2016;67(21):2453-63.

\section{Publisher's Note}

Springer Nature remains neutral with regard to jurisdictional claims in published maps and institutional affiliations.

Ready to submit your research? Choose BMC and benefit from:

- fast, convenient online submission

- thorough peer review by experienced researchers in your field

- rapid publication on acceptance

- support for research data, including large and complex data types

- gold Open Access which fosters wider collaboration and increased citations

- maximum visibility for your research: over $100 \mathrm{M}$ website views per year

At $\mathrm{BMC}$, research is always in progress.

Learn more biomedcentral.com/submissions 